\title{
Using the theory of planned behaviour to assess if psychosocial determinants of fruit and vegetable intake in a UK adult population change following a dietary intervention
}

\author{
T. D. Eggers ${ }^{1}$, G. Herbert ${ }^{2}$, T. W. George ${ }^{1}$, M. F. Chong ${ }^{1}$, J. A. Lovegrove ${ }^{1}$, L. Butler ${ }^{2}$, O. B. Kennedy ${ }^{1}$ \\ and the FLAVURS Team \\ ${ }^{1}$ Dept of Food and Nutritional Sciences and ${ }^{2}$ Dept of Psychology, University of Reading, Reading RG6 6AP, UK
}

The UK Department of Health recommends the consumption of at least five portions of fruit and vegetables (F\&V) a day, but only a third of British men and women are thought to meet this target ${ }^{(1)}$.

This study evaluated whether a dietary intervention (FLAVURS) that seeks to modify F\&V intake (FVI) directly in a low-consuming group also changes key underlying psychosocial determinants of behaviour. A sample of low-F\&V ( $\leq 3$ portions/d) consumers consisting of 154 adults, participated in a randomised controlled study. The intervention group received dietary advice and F\&V and the control group was encouraged to consume their habitual diet. Consumer perceptions of FVI were measured pre- and post-intervention (18 weeks apart) using a questionnaire based on the theory of planned behaviour (TPB) ${ }^{(2)}$ in 136 participants. The TPB proposes that behaviour is determined by a combination of people's intentions to engage in that behaviour and their perceptions of control over the behaviour. Intention (INT) in turn, is held to be predicted by attitudes (ATT) towards the behaviour, subjective norm (SN) and perceived behavioural control $(\mathrm{PBC})^{(3)}$. Individual questionnaire items were based on psychosocial determinants of FVI using seven-point, unipolar response scales $^{(4)}$. All constructs were coded so that higher numbers always reflected a more positive attitude. The questionnaires had separate sections for fruit and vegetable intake and were presented in a balanced order to participants.

\begin{tabular}{|c|c|c|c|c|c|c|c|c|c|c|c|c|c|c|c|c|c|}
\hline \multirow{3}{*}{ TPB Construct } & & \multicolumn{8}{|c|}{ Fruit } & \multicolumn{8}{|c|}{ Vegetable } \\
\hline & & \multicolumn{4}{|c|}{ Intervention } & \multicolumn{4}{|c|}{ Control } & \multicolumn{4}{|c|}{ Intervention } & \multicolumn{4}{|c|}{ Control } \\
\hline & & $\overline{\mathrm{N}}$ & $\mathrm{M}^{*}$ & SD & Sig. $\dagger$ & $\mathrm{N}$ & $\mathrm{M}$ & $\mathrm{SD}$ & Sig. & $\overline{\mathrm{N}}$ & $\mathrm{M}$ & SD & Sig. & $\mathrm{N}$ & $\mathrm{M}$ & SD & Sig. \\
\hline Pre & INT & 90 & 6.1 & 1.12 & $0.02^{\mathrm{a}}$ & 46 & 6.01 & 1.13 & 0.96 & 89 & 5.9 & 1.11 & 0.5 & 46 & 5.5 & 1.37 & 0.61 \\
\hline Post & INT & 90 & 6.39 & 0.94 & & 46 & 6 & 1.38 & & 89 & 5.99 & 1.07 & & 46 & 5.41 & 1.37 & \\
\hline Pre & ATT & 84 & 6.54 & 0.67 & 0.89 & 43 & 6.51 & 0.76 & 0.94 & 87 & 6.42 & 0.68 & 0.67 & 45 & 6.41 & 0.72 & 0.17 \\
\hline Post & ATT & 84 & 6.55 & 0.65 & & 43 & 6.51 & 0.8 & & 87 & 6.38 & 0.72 & & 45 & 6.23 & 0.98 & \\
\hline Pre & $\mathrm{SN}$ & 83 & 4.67 & 1.07 & 0.28 & 44 & 4.46 & 1.03 & 0.14 & 88 & 4.53 & 0.95 & 0.21 & 46 & 4.27 & 0.98 & 0.65 \\
\hline Post & $\mathrm{SN}$ & 83 & 4.54 & 1.05 & & 44 & 4.2 & 0.97 & & 88 & 4.4 & 1.06 & & 46 & 4.21 & 1.07 & \\
\hline Pre & PBC & 86 & 6.19 & 0.92 & 0.28 & 46 & 5.99 & 0.93 & 0.7 & 82 & 5.94 & 0.96 & 0.22 & 45 & 5.53 & 1.12 & 0.82 \\
\hline Post & PBC & 86 & 6.25 & 0.81 & & 46 & 5.93 & 1.11 & & 82 & 5.81 & 0.89 & & 45 & 5.5 & 1.17 & \\
\hline
\end{tabular}

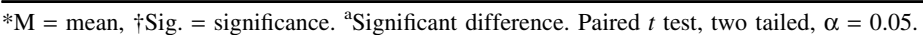

From the analysis of direct constructs only, there was evidence of a change in intention to eat fruit as a function of the intervention. A significant difference was found between the mean scores of the intervention and the control group with regard to consumers' intention to eat at least two portions of fruit as part of their ' 5 a day' $(P=0.02)$, but not for the intention to eat at least three portions of vegetables $(P=0.50)$. No differences were found for the three principle TPB constructs: ATT, SN and PBC for fruit or vegetable consumption. The evidence of a change in intentions to eat fruit is encouraging because any long-term change in behaviour requires changes in underlying cognition. Thus, short dietary interventions may be successful in producing longer-term dietary change, but research into the contribution of indirect constructs on intention to consume $\mathrm{F} \& \mathrm{~V}$ is needed.

FLAVURS study is FSA funded. TD Eggers received a Nuffield Undergraduate Bursary (2009).

1. Bates B, Lennox A \& Swan G (2010). London: Food Standards Agency and Department of Health.

2. Ajzen I (1991) The theory of planned behavior. Organ Behav Hum Decis 50, 179-211.

3. Povey R, Conner M, Sparks P et al. (2000) Br J Health Psychol 5, 121-139.

4. Herbert G (in preparation) PhD Thesis, University of Reading. 